\title{
Uma nova visão da análise dos atos de aposentadoria a cargo do TCE/RJ: um caso de ensaio de custos para retorno socioeconômico
}

\author{
Valderez Ferreira Fraga \\ Universidade Federal do Rio de Janeiro \\ Virgílio de Oliveira Souza \\ Universidade do Grande Rio
}

\begin{abstract}
Uma discussão sobre a complexidade da teoria da administração pública favoreceu a contextualização de um ensaio de caso, munido de um instrumento gerencial para melhores práticas. A expectativa de um espírito de servir público, a partir da inclusão de custos na análise dos atos de aposentadoria, é delimitada pela realidade brasileira do Tribunal de Contas (RJ), preocupada com a atividade dos servidores encarregados do cumprimento dos dispositivos legais relacionados, inferindo-se que a "tarefa", além de instrumental e tecnicamente confiável, pode ser fonte de autoestima, devido ao seu mérito social. Seu benefício à qualidade da gestão pública, com austeridade e o zelo ético pelo público, orientou o debate teórico e a construção instrumental, para um sentido de acolhimento à interação teoria e prática que, afastada do gerencialismo, não relega "deveres" gerenciais sobre custos legalmente instituídos. Considerações finais reconhecem o labirinto da administração, transformando seu emaranhado em instigante investigação, na desafiadora ciência-arte de escutar o povo, para respeitar a res publica que lhe pertence, como permanente labuta por compreensão.
\end{abstract}

Palavras-chave: teoria da administração pública; atos de aposentadoria; servir público.

\begin{abstract}
A new vision of retirement acts under the Estate of Rio de Janeiro Audit Court: a tentative case on costs for socioeconomic return

A discussion around the complexity of Public Administration Theory favored the contextualization of the included tentative case study which is supplied with an instrument in search for better practices. The expectations of a public serving spirit, from the inclusion of costs on the retirement acts analysis - delimited by the Brazilian reality of the RJ state Audit Court, preoccupied with the activity of public servers in charge of the related legal determinations compliance, inferring that the "task" besides of a technically trustful instruments, can also be a source de self esteem, due to its social merit. Its benefit toward the quality of public management, in terms of austerity and ethical zeal for the people, has
\end{abstract}

Artigo recebido em 20 mar. 2011 e aceito em 20 jul. 2011.

RAP - Rio de Janeiro 46(3):879-908, maio/jun. 2012 
oriented the theoretical debate and the instrumental construction toward a sense of sheltering theory and practice interaction. Away from managerialism, does not relegate legally instituted duties on costs. Final considerations recognize the labyrinth of Administration theories, transforming its entanglement into an instigating investigation on that challenging science-art of listening to people, respecting the res publica which belongs to him, as a permanent struggle for comprehension.

KEY WORDs: public administration theory; retirement acts; public serving.

As relações entre o saber e o fazer sempre constituíram um tópico importante do pensamento ocidental e continua a sê-lo. Nada justifica que nos afastemos dele e o abandonemos como insolúvel na área da administração.

Carlos O. Bertero

\section{Contextualizando e justificando a motivação}

A atual tendência à teoria gerencial na administração pública no país estimulou o reconhecimento do emaranhado em que ainda se encontra o estudo das teorias da administração pública, constatado em descrições e análises aprofundadas, como é o caso de Friederickson e Smith (2003) e de Miller e Fox (2007), cada uma das parcerias ao seu próprio modo. Por essa razão, pelo menos uma breve discussão sobre teoria e teoria da administração pública foi considerada fundamental, para dar sentido à escolha e tratamento do problema central deste estudo que é, na verdade, um pequeno-grande desafio, pois se refere à significância do trabalho do servidor público diante da análise dos "atos de aposentadoria".

A motivação para este estudo surgiu da busca por sustentação teórica para investigar um problema de gestão, relativo às atribuições de servidores do TCE, implicando a expectativa humana de significância na realização desse trabalho, em termos motivacionais e de resultados, fazendo uso de fundamentos gerenciais na administração pública.

A atração exercida pelo gerenciamento dito científico, a partir de F.W. Taylor, levou a modernidade à gestão pública com a Escola Clássica da Administração na expectativa de encontrar a melhor maneira (Vasconcelos e Vasconcelos, 2004). Muito do que foi emprestado dos negócios e aplicado à gestão governamental, no século XX, baseou-se em Taylor, seguindo-se, em especial, Chester Barnad, Henri Fayol e Luther Gulick (Friederickson e Smith, 2003).

É importante constatar, neste ponto, que diversificação e complexidade teórica atual, porém, não é algo inusitado sem base e sem história. Ela tem, além de um difuso passado longínquo, outro apenas centenário, rico e vivo, que veio rapidamente conquistando espaço na literatura, como é o caso do pioneirismo de Dwight Waldo. Ele "ampliou a perspectiva da teoria" da administração pública "a ordenando" e "levantando seus pontos significantes". Com essa contribuição, Waldo abriu caminhos para "artigos e livros de peso em administração pública" a um número elevado de estudos, comprovando que ela "faz sentido". Além disso, Dwight Waldo é lembrado por sua postura de antevisão da complexidade para a qual rumaria, 
dizendo que: "não deveríamos ter medo de teoria, porque, somente na teoria, no processo de testá-la, é possível entender a administração pública" (Friederickson e Smith, 2003:7).

Este estudo não tem a pretensão de retomar a teoria da administração pública para dotá-la de maior consistência. Empenha-se, ao reler selecionadas posições de autores reconhecidos, em poder dar fundamentação teórica a uma aspiração que surgiu da prática, no sentido da cidadania, relativa ao trabalho do servidor público, contextualizado, situado, a fim de sugerir uma reflexão sobre seu papel e possíveis contribuições, para sua própria dignidade, bem como para um complexo outro, resumido à densidade do povo, fim último da teoria e da prática da administração pública.

Em sendo o TCE uma casa cuja missão é a vigilância à probidade diante das res publica, do risco da ignorância da lei ou da corrupção, revela-se uma organização que precisa se perguntar a cada momento com Jaspers: "afinal admitimos ou não admitimos que todos compartilham de uma humanidade comum?” (Jaspers apud Fraga, 2009:119), já que o povo brasileiro está à espera, e que o mundo precisa urgentemente de postura e ações exemplares. As manifestações do TCE precisam ser ad rem.

\section{Fundamentos: literatura}

Para justificar o emprego de teoria da administração pública, Friederickson e Smith (2003) a consideram, na origem dos eventos humanos, tão antiga quanto a civilização, permeando o desenvolvimento social, que passa pelo Ocidente feudal, pela tradição chinesa, e requer autoridade formal. Porém, assinalam os autores: "o estudo formal da administração pública e a elaboração da teoria são relativamente novos" (Friederickson e Smith, 2003:2); logo, quer em relação às práticas profissionais, ou sob a forma de política, ou da chamada construção social da realidade, ela ainda seria uma adolescente.

Hood (2000) enfatiza que a chamada arte do Estado pode ser resumida a como planejar e operacionalizar os serviços públicos e reputa a formalização do estudo dessa área de conhecimento, há mais de uma década, especialmente aos países de língua inglesa, através de vasta literatura (Hood, 2000:1). Ele justifica essa sua percepção da realidade, afirmando que administração pública surge, na verdade, como um movimento que procura rever a burocracia.

Com essa posição, porém, Hood (2000) não quer dizer que a teoria gerada seja homogênea ou que seu emprego possa ser amplo, ao contrário, ele é contundente ao afirmar que, em suas diferenças no contexto, nas culturas, a teoria exige reflexão e empregos singulares. Daí a ideia de melhores maneiras — no plural — em tempos e lugares definidos. Nessa discussão, também, pontua a questão terminológica, dizendo que, ao renomear administração para gerenciamento, no caso público, revela-se a "transformação milenar para novo estilo" (Hood, 2000:1), modernizando, no sentido de aproximá-la de "melhores práticas" de negócio, e, ambiguamente, em busca de valores, saindo da "pobreza burocrática" para uma nova filosofia gerencial "baseada em valores" (Hood, 2000:3-4, 176). 
Não se trata de excludências, mas de possibilidades ao perceber a vastidão da gestão pública e, segundo Hood (2000), de reconhecer a inexorabilidade da globalização, acolhendo a complexidade da realidade desafiadora, ao que se sugere: empenho em pesquisa. Em decorrência, lembra o referido autor que rigidez ou negação de teoria na ambiguidade, sob o argumento de suas fraquezas, não traz segurança. Se a negação pode evitar estereótipos ou apego a pacotes ditos teóricos, por outro lado, bom senso e sabedoria, apesar de fundamentais, são insuficientes para dar conta. Daí, também, a centralidade da teoria na gestão pública (Hood, 2000:3).

\section{Teoria em administração pública: flashes da complexidade}

Nessa trajetória, a complexidade da administração pública seria a razão de sua multidisciplinaridade, não de sua fraqueza. Como o "campo é tanto interdisciplinar quanto aplicado, (...) nenhuma teoria solitariamente seria capaz de dar conta da complexidade da área" (Friederickson e Smith, 2003:4). Atualmente, um ponto crítico da discussão estaria no possível desequilíbrio teoria e prática, sobre o qual Bertero (2004) alerta com propriedade quando algumas linhas de pesquisa criticam o afastamento entre busca de soluções práticas e fundamentos teóricos, isto é, a teoria estaria sendo relegada a segundo plano, na moderna administração pública.

Este estudo se justifica justamente por assumir uma posição de cautela diante de possível gerencialismo, isto é, nem perder de vista a necessidade de uma base conceitual e nem descartar o papel que a teoria gerencial pode desempenhar com sua lógica e procedimentos. $\mathrm{O}$ que os limites deste estudo não permitiram abordar mais claramente foram as razões que levaram cada autor citado a considerar a complexidade teórica da administração pública, quer nas parcerias citadas, como Martins e colaboradores (2010), ou individualmente, como Harmon (1995), que manifesta sua perplexidade sobre responsabilidade e comprometimento com o outro, desvelando paradoxos. Polissemia, talvez, fosse um conceito a ser explorado, diante desses olhares sobre a teoria da administração pública.

\section{Iniciação ao entendimento de teoria}

Refletir sobre teoria tornou-se uma questão básica. Nas ciências físicas, teoria é vista como teste rigoroso de hipóteses preditivas, capazes de reconhecer e medir fenômenos naturais, podendo servir à prática; um segundo momento trata de teoria nas ciências sociais, que, na administração pública, é entendida como ordenamento de material factual, apresentando evidências através de conceitos, definições, metáforas, favorecendo a compreensão, baseada na intuição rigorosa do comportamento social, organizacional, sistema político, comunicação e cultura; em um terceiro momento, o significado de teoria, na administração pública, é de natureza normativa, trata do que deve ser, faz pontes com a ciência política e a filosofia e guia 
a alocação da res publica, descreve comportamentos normativos e suas implicações (Friederickson e Smith, 2003.).

Seu principal critério de teste é a empregabilidade, logo, utilidade, organização e classificação de dados, fortalecimento da compreensão, descrição e explicação, predizendo o que pode dar validade. Porém, a teoria apresenta variações de acordo com seu objeto ser geral organizacional, operacional, específico ou genericamente político (Friederickson e Smith, 2003).

Conscientes da complexidade teórica no campo da administração pública, Friederickson e Smith (2003) contribuem com um resumo de várias estruturas intelectuais para abordagens ao desempenho das teorias em administração pública, apresentando um procedimento - tabela, visando medir até que ponto os objetivos de cada uma dessas vertentes atingiria seus objetivos. Esse resumo compõe-se da base a seguir, estruturada pelos referidos autores:

Dimensões de uma teoria e habilidade que cada uma pode apresentar:

Parcimônia e elegância: contabilizar concisamente o fenômeno estudado, de forma ordenada.

Explanatória: explanar o fenômeno do mundo real.

Replicabilidade: generalizar além dos limites de um caso ou casos à mão.

Capacidade descritiva: retratar o mundo real precisamente conforme observado.

Predizibilidade: geração de hipóteses testáveis e acesso probabilístico ao futuro.

Garantia empírica: relativo sucesso em obter confirmação empírica de hipóteses e probabilidade que aventou. (Friederickson e Smith, 2003:230)

A leitura atenta à trajetória das teorias da administração, segundo Friederickson e Smith (2003:231), pode esclarecer que o resumo e o quadro de medição não são sinônimos de tradicionalismo metodológico ou tendência a excludências, mas reconhecimento das diferenças como tal, não necessariamente melhores ou piores, segundo a pontuação.

Reconhecem, por exemplo, que a teoria pós-moderna seria a maneira mais certa de pensar o mundo do que uma ferramenta para explicá-lo. Com isso, porém, autores mais ligados ao positivismo, em busca de explicações sistemáticas, através de casos empíricos, tenderiam a:

ver o pós-modernismo como desorientado giroscópio intelectual. (...) todavia, apesar da Teoria Pós-Moderna não parecer assentar-se confortavelmente na estrutura explícita ou implícita dos objetivos positivistas, o seu serviço à administração pública é considerável. No mínimo, ela tem provido uma vigorosa crítica sobre como conceituar e pensar a respeito dos elementos centrais da disciplina. (Friederickson e Smith, 2003:239)

\section{A categoria social é intima à administração pública}

Neste estudo, o enredamento percebido anteriormente não é considerado um defeito, mas uma realidade e, por outro lado, a aceitação de que, nesta atualidade profusa de referenciais 
e confusa na aplicação à prática, é preciso lucidez para não abandonar todos os constructos. Diz Jaspers que "verdade se coloca acima da ciência", lhe traz "clareza máxima"(apud Fraga, 2009:99; Jaspers, 1965:78). É necessário esquecer ortodoxias e procurar algum alento para ir administrando a res publica — nessa, talvez, pós-modernidade —, os problemas concretos que afligem os cidadãos.

Não é que se acredite muito em vida cidadã ou que se possa falar com certa coerência em povo, como servidor e membro da sociedade, mas o ser humano que leva a esse paradoxo revela a única saída para a solução da complexidade das misérias, da opulência e dos desvios de poder, quando, por exemplo, a massa cinzenta chamada de classe média tenta pensar e sobreviver, enquanto nem consegue gerar e quase nem sonhar com a possibilidade de ser ouvida em seus clamores abafados. Frágil, quase não aparece como objeto concreto, nem como parte de objetivos nas políticas públicas que mereçam tal qualificação.

As políticas públicas dos governos devem ocupar-se basicamente da construção desse elo cognitivo entre as realidades socioculturais dos diversos grupos que compõem o povo brasileiro.

\section{Peculiaridades da teoria da administração pública}

Com esse breve resumo baseado em Friederickson e Smith (2003), introduz-se a ideia de que, na teoria da administração pública, a expectativa por precisão e generalização é importante, porém sob alto custo, tendo em vista que "quanto mais uma teoria é precisa e é popular, no presente, isto é, contingente, maior o poder de servir a amplo espectro de acontecimentos e, portanto, o seu poder de predizer uma gama de fenômenos similares é reduzido" (Friederickson e Smith, 2003:6). Por essa razão, consideram que generalizações obtidas com simplificação só conseguem explicar o óbvio.

Miller e Fox (2007), por sua vez, seguem uma trajetória de leitura das teorias da administração orientada para a discussão modernidade/pós-modernidade, senão ceticamente, pelo menos agudamente desconfiada, começando por analisar criticamente a representatividade democrática, que entende a palavra povo como uma metáfora, segundo a qual a soberania popular estaria mesmo presente nas decisões, uma "pressuposição que consideram altamente problemática" (Miller e Fox, 2007:5).

Porém, ambos concluem o debate considerando-se otimistas, sem deixar de reconhecer como suscetível à tirania a maioria democrática com suas "premissas individualistas". Em decorrência, lembram a opção consociacionista - a exemplo dos países baixos - com a quebra desse individualismo, porém com a possibilidade de reforço de divisões internas, enquanto os que acreditam na democracia representativa apostam na soberania da grande metáfora: $o$ povo (Miller e Fox, 2007). Durante a jornada, passam pela posição teórica do construtivismo social, discutem governabilidade e racionalidade, constitucionalismo e comunitarianismo.

Miller e Fox (2007) enfatizam, ainda, que nenhuma alternativa em administração pública é neutra, seja a tendência liberal — a neo - que desabilitaria o governo, submetendo-o 
à inefetividade e distribuindo magros ganhos às pessoas nas organizações, ou o constitucionalismo, que julgam muito conservador diante do que se propõe. O comunitarianismo espera que cada cidadão participe diretamente das decisões que afetam suas vidas, como parte da "teleologia de ser integralmente humano". Além das várias dificuldades dessa proposta, indicam como ponto fraco que "a comunidade pode não estar suficientemente atenta para resolver ambos, os seus problemas públicos ou os nossos” (Miller e Fox, 2007:125).

O caso prático descrito e discutido neste estudo desencadeou esse roteiro para analisar a teoria, estimulando uma reflexão sobre a postura de cada proposta teórica no referencial construído e uma atitude de busca do em comum. Na verdade, a reflexão voltou-se para o servir público autêntico no sentido da mutualidade, isto é, quem presta o serviço pode ter plena consciência do exercício de seu papel pró-cidadania e o serviço, em si, é implementado e avaliado tanto em termos técnicos quanto o é em sua efetividade social.

Diante desse panorama, parece ainda importante discutir gestão do setor público enquanto sistema de custos como instrumento de eficiência estratégica.

Segundo Cavalcanti (2006:287), há que se reconhecer na administração pública uma "diferenciação na macroestrutura burocrática para se poder enfrentar os desafios e incertezas inerentes às tarefas do desenvolvimento", o que reduziu as várias reformas a "atitudes reticentes e incoerentes (...) de avanços e recuos". Cavalcanti, a partir do quadro atual da Administração Pública, citando Gulick e Urwick (1937) e Willoughby (1927, 1936), aponta que o Brasil ingressa nessa visão gerencial contemporânea, porém mantendo o enfoque jurídico dos problemas de administração e destaca o pensamento de Wahrlich (1976:50), considerando a administração pública "seara do direito administrativo, com ênfase na legalidade e nos rituais processualísticos" de procuradores e advogados.

Diante da estrutura burocrática instituída, prevaleceria uma administração paralela que convive com esse sistema legalista, apresentado por Cavalcanti (2006) como concessões à diferenciação, não realizando uma reforma profunda na atuação do governo. Empregando a metáfora da "gestão equalizadora" à leitura da práxis como servidor público, pode-se ousar afirmar que, na prática, a administração pública não é proativa do ponto de vista econômico, trabalhando somente com base no orçamento financeiro, isto é, o aparelho estatal crescendo sem racionalidade.

A equalização sugerida por Cavalcanti (2006) revela busca por um conceito capaz de dar conta das dimensões técnicas, políticas, culturais e humanas da organização. A visão burocrática bloquearia a reforma da administração, em contraste com uma visão de custos como instrumento efetivo de gerenciamento da administração, como a visão gerencial "equalizadora" com um caráter de implementação continuada.

Entenda-se que gerência mediante sistema de controle de custos é exigida desde a Lei no 4.320, de 1964, reforçada pelo Decreto-Lei no 200, de 1967, relembrado pela Lei de Responsabilidade Fiscal (LRF) e, agora, com as Normas Brasileiras de Contabilidade Aplicadas ao Setor Público (NBCASP).

Bresser-Pereira (2006:21), no livro Reforma do Estado e administração pública gerencial, afirma que: "para podermos ter uma administração pública moderna e eficiente, compatível com 
o capitalismo competitivo em que vivemos, seria necessário flexibilizar o estatuto da estabilidade dos servidores públicos de modo a aproximar os mercados de trabalho público e privado".

Conduzindo o Plano Diretor da Reforma do Aparelho do Estado (PDRAE), BresserPereira (2006:22) tinha como proposta transformar a administração pública brasileira de burocrática em gerencial.

Da proposta inicial pode-se observar que, visando à eficiência, apontava diretamente como causa a mão de obra direta dos servidores públicos sem, contudo, apresentar um instrumento que possibilitasse a mensuração e a geração de indicadores de eficiência. Ora, se fosse pensado em criar esses indicadores mediante um sistema de análise de custos efetivo, a dita reforma não seria norteada para a flexibilização do estatuto da estabilidade dos servidores públicos, pois ela não é, ainda hoje, suprema (definitiva).

Não parece haver sido considerado o fato de que a CF/1988, em seu art. 37, esculpe os princípios que regem a administração pública e, entre eles, o da eficiência. Em decorrência, o que falta, até hoje, para que se possa mostrar a eficiência ou ineficiência da administração pública e de seus agentes é um instrumento de análise de custos que indique eficiência da ação pública, levando em conta os insumos que entram no processo produtivo e o retorno social esperado (saídas).

A transição de uma administração pública burocrática para uma visão gerencial não deve prescindir de um sistema de custos, lembrado por Mauss e Souza (2008) bem como por Cruz e Neto (2007), ao destacarem que a legislação brasileira vem buscando essa administração gerencial desde a Lei no 4.320/1964 (art. 99), em seguida, com o Decreto-Lei no 200/1967 (art. 79) e, mais recentemente, com a Lei de Responsabilidade Fiscal (LRF), art. 50, § 3․

Bresser-Pereira (2006:28) afirma que a administração pública emergiu "como resposta à crise do Estado, como modo de enfrentar a crise fiscal, como estratégia para reduzir o custo e tornar mais eficiente a administração". A parte final dessa citação leva a inferir que não se alcançará uma gestão pública gerencial sem que se tenha uma visão gerencial sobre custos, para que se possa determinar que reduções de custos podem ser implementadas e quais indicadores de desempenho apontarão a eficiência ou não da gestão.

Donald F. Kettl (2006:87) defende que "as tendências favoráveis à gestão pública (...) baseiam-se, também, na possibilidade de avaliar o desempenho do aparelho do Estado". O que é reforçado por Maus e Souza (2008), declarando que não se consegue o gerenciamento da administração pública sem um controle de custos para lhe oferecer parâmetros e mecanismos que fundamentem o planejamento e a mensuração do resultado das atividades públicas, ou seja, amparo à tomada de decisões, controle gerencial e accountabillity, entendida como transparência.

Reforçam, em conclusão, que "o compromisso com a ideia de avaliar resultados é a base essencial do movimento global de reforma do setor público" (Kettl, 2006:89). Nessa linha de raciocínio, "as avaliações de desempenho precisam ocorrer em dois planos diferentes: no da produção", "e no dos resultados". Conforme destacado, "apesar de todas as dificuldades, a mensuração do desempenho passou a ser o item mais importante da revolução global da administração pública" (Kettl, 2006:96). Desde os aspectos introdutórios, segundo Mauss e 
Souza (2008) até as palavras de Kettl (2006), percebe-se que os autores consideram haver um descolamento entre discurso e ação em torno da avaliação de desempenho, um desafio que parece persistir na gestão de pessoas, merecendo pesquisa ampla. De uma forma mais contundente, Kettl afirma que "é mais útil trabalhar na direção de uma administração baseada em desempenho que em uma baseada na avaliação do desempenho" (Kettl, 2006:95).

\section{Metodologia: o problema, os objetivos, a postura, o que e como fazer}

Enquanto a celeuma teórica continua e a realidade problemática persiste, a visibilidade de pequenos, mas impactantes problemas, acorda gestores/pesquisadores públicos em busca de fundamentos e métodos para melhores práticas. Daí esta pesquisa qualitativa, que se utiliza de quantitativos para construir um caso de ensaio ilustrativo, recorrer, ainda, à pesquisa bibliográfica documental para fundamentá-la e incluir o campo, no sentido foucaultiano, conforme o descreve Peci (2004:36): "é no campo que se manifestam, que se cruzam, que se emaranham que se especificam as questões do ser humano, da consciência e do sujeito". A postura de abertura assumida nesta pesquisa, no sentido de aprender com o convívio no trabalho, gerar um exemplo de instrumento gerencial, apreender motivações nas relações de um servir público autêntico, pode parecer ambiciosa, porém é consciente de seu caráter de ensaio. A motivação para enfrentá-la foi buscar, no convívio com a fala do fazer, do proceder no trabalho, talvez, como costuma interpretar Focault, citado por Souza (2000:531), "instintivamente", o "murmúrio que não se ouve", o que ele descrevia como "uma fala que não cessa" e cujo "esplendor" seria "o povo", ao que caberia acrescentar-se: uma motivação inerente à missão de um TCE.

Sendo uma limitação deste estudo a delimitação pela realidade brasileira e as atuações do TCE, o espírito do servir público que o moveu buscando autenticidade apresenta-se como universal.

Diante da atual tendência, há o temor de a chamada nova administração pública recair no gerencialismo ou, em contraste, de estimular o reconhecimento da complexidade teórica como um empecilho, alertando, ainda, sobre riscos de ignorá-la. Por outro lado, pode também estimular uma flexibilidade habilidosa, cautelosa, porém ativa diante do problema apresentado na introdução e foco central deste estudo: a busca por contribuição socioeconômica com o que é realizado pelos servidores públicos, sua economicidade concreta, além da promoção do exercício da cidadania. Essa é a posição assumida por Dejours (1993) e destacada por Vasconcellos e Vasconcelos (2004:122) sobre a "validade ética e estética do trabalho (...) reconhecimento conferido pelos pares ou pelo grupo social, e influenciam na motivação dos indivíduos (...) no conceito que desenvolvem sobre si próprios".

Voltando ao instrumental, sem cogitar pesquisa operacional - atração em engenharia na gestão - , apenas assume-se a postura gerencial que lida com contabilidade, valores relativos a custo-benefício de um serviço prestado pelo TC, no caso, TCRJ. Foram, assim, levantados dados a fim de melhorar a visibilidade das ações na gestão e, simultaneamente, 
a considerar o intangível: encontrar formas de fazer aparecer o justo sentido de significância aos que realizam esse serviço público, no nível tarefa ou no julgamento do mérito sociotécnico do objeto de atenção. Pesquisando-se esse objeto em suas duas faces - a tangível, da análise dos atos de aposentadoria, e a intangível, de suas implicações como servir público —, almeja-se dar mais um passo no sentido da aplicação teórica e obter algum avanço no sentido da cidadania: pelo reconhecimento do trabalho, pelas revelações de boas práticas na gestão, incluindo custos, pela recuperação da confiança fundamentada, em substituição à burocratização em anonimato. Na verdade, a preocupação com custos, neste estudo, pode causar estranheza, porém não se reduz ao sentido econômico-financeiro. Não consiste, portanto, no caminho mais simples; mas, sim, no mais desprendido de valores tão arraigados a "estratégias de mercado", de poder ou "origens em grandes estratégias de guerra", pois se considera que "as políticas públicas deveriam ser baseadas no amor" (Zouain e Torres, 2005:203), no amor ético, segundo Hannah Arendt (2003).

Cabe, pois, aqui, recorrer a Friederickson e Smith (2003:98) para caracterizar a teoria gerencial, tomada como "processos formais e informais que guiam a interação humana em direção aos objetivos organizacionais. A unidade de análise são processos de interação entre gerentes e servidores, os efeitos do comportamento gerencial sobre os trabalhadores e os resultados do trabalho". Neste estudo, o alvo é o processo de aposentadoria, em seu significado de custo para o setor público e de ganho motivacional, ou não, na realização do trabalho de analisá-lo, compreendê-lo melhor como processo técnico e social, divulgá-lo, reconhecendo seu objetivo maior de respeitar a Constituição, neste caso do TCRJ.

Finalmente, este estudo objetiva oferecer um instrumento construído para melhoria de procedimentos e processos - motivo prático — para favorecer uma visão um pouco mais ampla e menos superficial das implicações socioeconômicas desse trabalho, somando-se à busca por melhor compreensão de sua significância, tanto para gestores quanto para beneficiários - motivo psicossocial. Além, ainda, de realizar uma breve retrospectiva da teoria da administração pública, apontando sua complexidade, sem deixar de reconhecer e recorrer a procedimentos da teoria gerencial - motivo teórico.

Sobre a crítica da academia: oscilando entre "bom gerenciamento, mas, não muito boa ciência", leva a concordar que "só o tempo dirá sobre seus efeitos" (Friederickson e Smith, 2003:125).

\section{Introduzindo o caso do ensaio}

As atividades desenvolvidas pelos Tribunais de Contas, em cumprimento à missão constitucional no exercício do controle externo, não são de fácil execução, demandando um alto custo na fiscalização. Essas atribuições de índole constitucional são as previstas no art. 71 e incisos da Constituição Federal, de 5 de outubro de 1988, entre elas, o registro dos atos de aposentadoria (inciso III). 
Nesse sentido, apresenta-se um cenário entre os custos envolvidos no exame dos atos de aposentadoria em relação ao retorno socioeconômico dessa atividade, disponibilizando ao gestor um ferramental que o possibilite tomar decisões sobre a hierarquia das atividades a serem desenvolvidas, otimizando a ação de fiscalização a cargo do Tribunal de Contas do Estado do Rio de Janeiro, sob um enfoque de custo de oportunidades.

A divisão da pesquisa em duas partes objetivou: avaliar o retorno socioeconômico da atividade de fiscalização dos atos de aposentadoria, levando-se em consideração a expectativa de vida do servidor e, além disso, realizar um ensaio de custos, adotando como espaço amostral o pessoal envolvido na atividade de análise de aposentadoria, na $3^{\text {a }}$ Inspetoria de Controle de Pessoal (3aㅡ IGP).

Nessa pesquisa, muito embora os obstáculos variados e de não ser o objetivo superá-los, embora sejam essenciais para o aprimoramento de outras pesquisas que tenham como escopo a análise de custos na administração pública, deseja-se disponibilizar instrumentos de decisão e de ação em que se considere o retorno socioeconômico versus o custo para definição da atividade a ser priorizada.

Este estudo, ao seu termo, visa a fomentar a continuidade da pesquisa até que sejam implantados sistema de custos nos órgãos da administração pública e sistema de tecnologia da informação que automatize o exame dos atos de pessoal.

\section{Objeto}

Administração pública, entre os princípios da Carta Magna, destaca a eficiência e a publicidade, essa última aqui entendida não como mera publicação, mas como visibilidade das atividades desenvolvidas.

Nesse sentido, este trabalho pode ser lido como uma ideia inicial de quantificação dos processos submetidos à Subsecretaria de Controle de Pessoal (SUP), visando a uma estrutura de pesquisa que possa suportar decisões a cargo do subsecretário, com relação: à prioridade de ação, ao direcionador dos recursos disponíveis e à adoção de procedimentos que possam otimizar a análise processual.

Dos processos submetidos às Inspetorias de Controle de Pessoal (IGP) da SUP, a análise foi iniciada com os atos de aposentadoria, tendo como meta inicial obter o valor de cada processo para o futuro e, assim, no seu todo, apresentar os reflexos dos trabalhos desenvolvidos pela SUP com relação a essas naturezas de processo.

Em um segundo momento, busca-se quantificar os custos envolvidos em cada processo, demonstrando a relação custo/benefício dessa atividade, ainda carente de maiores investimentos. Ressalta-se, porém, a delimitação dessa análise, restringindo-se a um ensaio, com relação aos gastos da $3^{\text {a }}$ IGP.

Nesse sentido, procura-se fortalecer a fiscalização na área de pessoal a cargo do Tribunal de Contas, mediante relatórios gerenciais que possam ser instrumentos de decisão e direcionadores da melhor aplicação dos recursos envolvidos — otimização da análise dos atos de pessoal. 


\section{Justificativa}

Entre as atividades desenvolvidas pelo Tribunal de Contas do Estado, há um incômodo mito com relação à fiscalização dos atos de pessoal, e esse sentimento repercute na autoestima dos técnicos que exercem essas funções na Subsecretaria de Controle de Pessoal: a sensação de estar executando "o trabalho de Sísifo".

\section{O mito de Sísifo}

Esse mito é usado para trabalhar uma metáfora sobre a vida moderna, como trabalhadores em empregos inúteis em fábricas e escritórios. "O operário de hoje trabalha todos os dias em sua vida e faz as mesmas tarefas. Esse destino não é menos absurdo, mas é trágico quando em apenas nos raros momentos ele se torna consciente" (Camus, 2002).

A iniciativa deste trabalho visa, pois, a constatação da importância dessa atividade em seu aspecto quantitativo, haja vista ser inequívoca em seu aspecto qualitativo e de ação de índole constitucional, não podendo o TCE deixar de implementá-la, otimizando procedimentos de análise.

Busca-se, então, responder o quanto vale a atividade de análise de registro dos atos de concessão de benefícios previdenciários pro futurum, não se detendo, integralmente, nessa análise inicial sobre tais custos envolvidos, quer com mão de obra direta quer com indireta, gastos indiretos, outros insumos e custos fixos.

Há muito se tem buscado eficiência dos gastos da administração pública; sobretudo, na área de pessoal. Portanto, o cerne da questão não é minimizar os custos da fiscalização dos atos de pessoal de forma irresponsável; mas, sim, otimizar esses gastos, repercutindo em resultados positivos para a sociedade em termos de eficiência e efetividade no sentido da relevância do humano, porque pode legitimar atos da gestão pública no mundo da vida (Fraga, 2009).

Em síntese, a Subsecretaria de Controle de Pessoal lança um novo olhar sobre as análises implementadas não como um mero ato para registro quase cartorial, mas como direcionadores para otimização de inspeções e/ou auditorias nas ações a seu cargo, examinando a legalidade, legitimidade e economia. Atuando, o faz em um sentido mais amplo, tomando o aspecto legal para a eficiência no método de trabalho, a eficácia considerando os custos e a efetividade, reconhecendo o social pela relevância do humano (Fraga, 2009).

\section{Metodologia para o ensaio de caso}

Para uma identificação inicial da situação, recorreu-se a relatórios do Sistema de Controle e Acompanhamento de Processos (Scap), listando todas as naturezas de processos submetidos à SUP e elegendo a natureza de processo a ser trabalhada, considerando a facilidade de acesso e a disponibilidade dos dados. Por essa razão, iniciou-se o trabalho pelos processos de aposentadoria.

A delimitação temporal escolhida para análise serviu-se do período compreendido entre 1ํ de maio e 10 de dezembro de 2009. A escolha do período não se deu ao acaso; pelo contrá- 
rio, procurou-se retirar da amostra os reflexos da reestruturação que ocorreu nos momentos iniciais daquele exercício, que teve maior impacto nos meses de janeiro a abril.

Os dados foram obtidos da análise do relatório inicial do Scap, que tem por natureza os processos de aposentadoria, relacionando cada qual com a respectiva planilha de dados e check list de preenchimento obrigatório no sistema de emissão de informações processuais — Infobase.

Os valores dos benefícios a serem pagos futuramente levaram em consideração a expectativa de vida dos brasileiros publicada pelo Instituto Brasileiro de Geografia e Estatística (IBGE), distinguindo se homem ou mulher.

Em relação ao ensaio propriamente dito de custos da análise dos atos de aposentadorias a cargo da 3a IGP e para obtenção dos gastos diretos e indiretos de mão de obra, adotou-se o sistema de questionários e, então, a composição dos valores de remuneração de cada servidor, considerando a tabela de cargos e salários.

Os gastos referentes a serviços indiretos constantes da folha de pagamento do TCE foram rateados em cada serviço/atividade e, ao final, foram rateados na atividade de aposentadoria e outras, tomando-se como direcionador de custo o valor real da folha de pagamento. Ressalte-se que os serviços indiretos dos quais se tratou na análise são os de segurança executados por bombeiros, recepção e portaria, análise e processamento informacional (CPD) e protocolo geral.

O consumo de material de expediente levou em consideração o relatório emitido pelo serviço de almoxarifado em que constam os materiais enviados para a 3 a IGP e a contagem do material existente na inspetoria, no final do exercício de 2009.

Os custos fixos (luz, água, telefonia e serviços de limpeza) constaram de relatório circunstanciado da Secretaria Geral de Administração (SGA), apropriados no mês de competência, tendo por base de rateio o total da folha de pagamento.

É mister ressaltar que não foram considerados os valores de depreciação e/ou amortização, haja vista não existir controle implantado que espelhe para a administração pública essa informação.

Em síntese, a metodologia empregada foi a da análise de conteúdo e confronto dos expedientes de aposentadoria com os registros constantes do Infobase e relatórios de gastos disponibilizados pela SGA.

\section{Análise dos resultados}

Este item visa apresentar o campo de pesquisa, os dados coletados e as informações obtidas após análise e discussão dos resultados nessa primeira parte da análise.

O campo de análise é a 3aㅗ IGP, tendo por espaço amostral, como já apresentado, os expedientes de aposentadoria.

\section{Achados da análise dos expedientes submetidos à $3^{a}$ IGP}

A 3 IGP, no período em análise, instruiu 2.261 atos de aposentadoria. Em cada expediente, técnicos preenchem uma planilha que retrata dados extraídos dos processos instruídos, o que os auxilia em algumas conclusões. 
A análise quantitativa deu-se em uma amostra de 381 expedientes que apresentavam informações completas na planilha. Além do aspecto quantitativo que se busca com o trabalho, foram obtidas informações qualitativas num espaço amostral de 503 de 2.261 processos, sendo essas relacionadas às sugestões de decisões, modalidades de benefícios, fundamentações e sexo dos segurados.

Assim, do total de processos listados, foram analisados 503, o que representa 22,25\% em seus aspectos qualitativos (conformidade/sugestão) e 381, isto é, 16,85\% do universo dos atos de aposentadoria analisados pela $3^{\mathrm{a}}$ IGP no período estudado em seu aspecto quantitativo (retorno socioeconômico $\times$ custo). Em síntese, a metodologia empregada foi a da análise de conteúdo e confronto dos expedientes de aposentadoria com os registros constantes do Infobase. Os administrativos que foram analisados pela Inspetoria, no período estudado, apresentam-se como demonstrado no quadro 1:

$$
\text { Quadro } 1
$$

\begin{tabular}{|c|c|c|}
\hline SECRETARIAS / ÓRGÃOS & QT. & $\%$ \\
\hline CAIXA ASSIS PREV PEN SER PUB PORCIÚNCULA & 2 & $0,09 \%$ \\
\hline CÂMARA NITERÓl & 1 & $0,04 \%$ \\
\hline DEGASE-DEPART GERAL AÇÕES SÓCIO-EDUCATIV & 2 & $0,09 \%$ \\
\hline FSC-FUNDAÇÃO SANTA CABRINI & 1 & $0,04 \%$ \\
\hline FUNDAÇÃO MUN EDUCAÇÃO NITERÓI & 30 & $1,33 \%$ \\
\hline FUNDO MUN PREVIDÊNCIA CARDOSO MOREIRA & 2 & $0,09 \%$ \\
\hline FUNDO MUN PREVIDÊNCIA ITALVA & 2 & $0,09 \%$ \\
\hline HOSPITAL PEDRO ERNESTO & 27 & $1,19 \%$ \\
\hline INST PREV SERV PIJBL CID SÃO JOÃO MERITI & 2 & $0,09 \%$ \\
\hline INST PREVID SERV NOVA IGUAÇU - PREVINI & 1 & $0,04 \%$ \\
\hline INST PREVIDÊNCIA CABISTA ARRAIAL DO CABO & 20 & $0,88 \%$ \\
\hline INSTITU PREV SOC SERV PUB MUN NATIVIDADE & 1 & $0,04 \%$ \\
\hline INSTITUTO BENEF ASSIST CABO FRIO-IBASCAF & 45 & $1,99 \%$ \\
\hline INSTITUTO PREV ASSIST CONCEIÇÃO MACABU & 1 & $0,04 \%$ \\
\hline INSTITUTO PREV SERV SÃO PEDRO DA ALDEIA & 3 & $0,13 \%$ \\
\hline INSTITUTO PREVIDÊNCIA LAJE DO MURIAÉ & 1 & $0,04 \%$ \\
\hline INSTITUTO PREVIDÊNCIA MUN CASIMIRO ABREU & 5 & $0,22 \%$ \\
\hline PREFEITURA BOM JESUS DO ITABAPOANA & 1 & $0,04 \%$ \\
\hline PREFEITURA CAMBUCI & 7 & $0,31 \%$ \\
\hline PREFEITURA CASIMIRO DE ABREU & 5 & $0,22 \%$ \\
\hline PREFEITURA MIRACEMA & 1 & $0,04 \%$ \\
\hline PREFEITURA NITERÓI & 2 & $0,09 \%$ \\
\hline PREFEITURA SEROPÉDICA & 5 & $0,22 \%$ \\
\hline
\end{tabular}




\begin{tabular}{|lrr|}
\hline \multicolumn{1}{c}{ SECRETARIAS / ÓRGÃOS } & QT. & \multicolumn{1}{c|}{$\%$} \\
\hline PREFEITURA VARRE-SAI & 3 & $0,13 \%$ \\
SEC EST ADM E REESTRUTURAÇ̃̃O (EXTINTA) & 18 & $0,80 \%$ \\
SEC EST ADMINISTRAÇÃO PENITENCIÁRIA & 16 & $0,71 \%$ \\
SEC EST EDUCAÇÃO & 1.926 & $85,18 \%$ \\
SEC EST FAZENDA & 46 & $2,03 \%$ \\
SUDERJ-SUPERINT DESPORTOS ESTADO RJ & 1 & $0,04 \%$ \\
TRIBUNAL DE JUSTIÇA DO ESTADO RJ & 8 & $0,35 \%$ \\
UENF-UNIV EST NORTE FLUMINENSE & 1 & $0,04 \%$ \\
UERJ-FUND UNIVERSIDADE DO ESTADO RJ & 75 & $3,32 \%$ \\
TOTAL & 2.261 & $100,0 \%$ \\
\hline
\end{tabular}

Fonte: Elaborado a partir do relatório Scap (maio/dez. 2009).

A natureza de processo selecionada não foi ao acaso, pois, tomando-se somente os processos principais em todas as naturezas de expedientes submetidos à $3^{\underline{a}}$ IGP, os processos de aposentadoria representam 92,02\%. Ademais, os reflexos dos proventos de aposentadoria para o futuro demonstram o quanto vale, efetivamente, essa atividade de fiscalização que não se resume, tão somente, em registro de legalidade.

Ressalta-se que, para a eleição da natureza a ser estudada, não foram computados os processos anexos e/ou apensos. Ver quadro 2:

\begin{tabular}{|lcc|}
\multicolumn{4}{c}{ Quadro 2} \\
\begin{tabular}{|lcc|}
\hline NATUREZinição do espaço amostral — 3a IGP \\
\hline Aposentadoria & QUANTIDADE & $\%$ \\
Comunicação & 2.261 & $92,02 \%$ \\
Comunicação Judicial & 14 & $0,57 \%$ \\
Concurso Público & 6 & $0,24 \%$ \\
Consulta & 44 & $1,79 \%$ \\
Contrato determinado & 12 & $0,49 \%$ \\
Dispensa de Licitação & 116 & $4,72 \%$ \\
Total & 4 & $0,16 \%$ \\
\hline
\end{tabular}
\end{tabular}

Fonte: Elaborado a partir do relatório Scap (maio/dez. 2009). 
Na linha de raciocínio desenvolvida, pode-se inferir que os relatórios gerenciais gerados, combinados com uma análise mais detida de custos, tornar-se-ão, à medida que se depurar a análise, um forte instrumento de gestão, podendo, inclusive, indicar as diretrizes para inspeção e o custo-benefício das atividades desenvolvidas pela SUP. Isso facilita a decisão do gestor em priorizar uma atividade à outra — custo de oportunidade. A amostra que detém informações completas apresenta-se resumida no quadro 3.

Para uma análise qualitativa do todo da amostra e, assim, poder inferir o todo em estudo (aposentadorias), foram incluídos os processos que não apresentam informações completas, considerando-se as instruções mais recentes, vez que já traziam o check list e informações da planilha, como consolidado no quadro 4.

$$
\text { Quadro } 3
$$

Expedientes com informações completas - maio/dez. 2009 - 3ạ IGP

\begin{tabular}{|c|c|c|c|c|c|}
\hline \multicolumn{6}{|c|}{ PROCESSOS COM INFORMAÇÕES COMPLETAS - MAIO A DEZEMBRO 2009} \\
\hline \multirow{2}{*}{ DESCRIÇÃO DOS DADOS } & \multicolumn{4}{|c|}{ QUANTIDADE } & \multirow{2}{*}{$\%$} \\
\hline & MODALIDADE & FUNDAMENTAÇÃO & SEXO & SUGESTÃO & \\
\hline VOLUNTÁRIA ESPECIAL - VE & 271 & & & & $71,13 \%$ \\
\hline VOLUNTÁRIA INTEGRAL - VI & 89 & & & & $23,36 \%$ \\
\hline INVALIDEZ INTEGRAL - || & 7 & & & & $1,84 \%$ \\
\hline INVALIDEZ PROPORCIONAL - IP & 6 & & & & $1,57 \%$ \\
\hline VOLUNTÁRIA PROPORCIONAL PO IDADE - VPI & 5 & & & & $1,31 \%$ \\
\hline COMPULSÓRIA INTEGRAL - CI & 1 & & & & $0,26 \%$ \\
\hline COMPULSÓRIA PROPORCIONAL - CP & 2 & & & & $0,52 \%$ \\
\hline ART. 6으 EC 41 & & 331 & & & $86,88 \%$ \\
\hline ART. 3 으 EC 20 & & 6 & & & $1,57 \%$ \\
\hline ART. 3으 EC 47 & & 5 & & & $1,31 \%$ \\
\hline REGRA PERMANENTE - RP & & 37 & & & $9,71 \%$ \\
\hline ART. $8^{\circ}$ EC 20 & & 2 & & & $0,52 \%$ \\
\hline MASCULINO - M & & & 42 & & $11,02 \%$ \\
\hline FEMININO - F & & & 339 & & $88,98 \%$ \\
\hline ARQUIVAMENTO NA ORIGEM - ARQ & & & & 0 & $0,00 \%$ \\
\hline DEVOLUÇÃO - DV & & & & 31 & $8,14 \%$ \\
\hline DILIGÊNCIA EXTERNA - DE & & & & 24 & $6,30 \%$ \\
\hline REGISTRO - RG & & & & 326 & $85,56 \%$ \\
\hline TOTALIZAÇÃO & 381 & 381 & 381 & 381 & - \\
\hline
\end{tabular}

Fonte: Papéis de trabalho elaborados pelo técnico. 
Quadro 4

Consolidação do espaço amostral - maio/dez. 2009 - 3a IGP

\begin{tabular}{|c|c|c|c|c|c|}
\hline \multicolumn{6}{|c|}{ CONSOLIDAÇÃO GERAL - 01/05 A 10/12/2009 - 3a IGP } \\
\hline \multirow{2}{*}{ DESCRIÇÃO DOS DADOS } & \multicolumn{4}{|c|}{ QUANTIDADE } & \multirow{2}{*}{$\%$} \\
\hline & MODALIDADE & FUNDAMENTAÇÃO & SEXO & SUGESTÃO & \\
\hline VOLUNTÁRIA ESPECIAL - VE & 302 & & & & $60,04 \%$ \\
\hline VOLUNTÁRIA INTEGRAL- VI & 101 & & & & $20,08 \%$ \\
\hline INVALIDEZ INTEGRAL - II & 13 & & & & $2,58 \%$ \\
\hline INVALIDEZ PROPORCIONAL - IP & 11 & & & & $2,19 \%$ \\
\hline VOLUNTÁRIA PROPORCIONAL POR IDADE - VPI & 12 & & & & $2,39 \%$ \\
\hline COMPULSÓRIA INTEGRAL - CI & 1 & & & & $0,20 \%$ \\
\hline COMPULSÓRIA PROPORCIONAL - CP & 5 & & & & 0,99\% \\
\hline NÃO IDENTIFICADO - XXX & 58 & & & & $11,53 \%$ \\
\hline ART. 6o EC 41 & & 352 & & & $69,98 \%$ \\
\hline ART. 3으 EC 20 & & 17 & & & $3,38 \%$ \\
\hline ART. 3으 EC 41 & & 1 & & & $0,20 \%$ \\
\hline ART. 3을 47 & & 7 & & & $1,39 \%$ \\
\hline REGRA PERMANENTE - R. P. & & 61 & & & $12,13 \%$ \\
\hline ART. 8 EC 20 & & 3 & & & $0,60 \%$ \\
\hline NÃO IDENTIFICADO - XXX & & 62 & & & $12,33 \%$ \\
\hline MASCULINO - M & & & 70 & & $13,92 \%$ \\
\hline FEMININO - F & & & 421 & & $83,70 \%$ \\
\hline NÃO IDENTIFICADO - XXX & & & 12 & & $2,39 \%$ \\
\hline ARQUIVAMENTO NA ORIGEM - ARQ & & & & 1 & $0,20 \%$ \\
\hline DEVOLUÇÃO - DV & & & & 55 & $10,93 \%$ \\
\hline ENCAMINHAMENTO - DESP & & & & 6 & $1,19 \%$ \\
\hline DILIGÊNCIA EXTERNA - DE & & & & 38 & $7,55 \%$ \\
\hline REGISTRO - RG & & & & 399 & $79,32 \%$ \\
\hline RECUSA - ILEG & & & & 4 & $0,80 \%$ \\
\hline NÃO IDENTIFICADO - XXX & & & & 0 & $0,00 \%$ \\
\hline TOTALIZAÇÃO & 503 & 503 & 503 & 503 & - \\
\hline
\end{tabular}

Fonte: Papéis de trabalho elaborados pelo técnico.

Diante da amostra estudada que totaliza 503 processos, i.e., 22,25\% do universo de atos de aposentadorias que foram trabalhados pela $3^{\text {a }}$ IGP, observou-se que em $16,85 \%$ do total de processos, os dados, após análise, conduzem às informações assim dispostas. 


\section{Quadro 5}

Análise resumida dos dados coletados - informações relativas a maio/dez. 2009 - 3a IGP Processos de aposentadoria analisados pela 3 IGP no período de 1o de maio a 10 de dezembro de 2009

\begin{tabular}{|c|c|c|c|}
\hline \multicolumn{4}{|c|}{ ANÁLISE NO ESPAÇO AMOSTRAL DEFINIDO } \\
\hline INFORMAÇÕES & VR & UFIR (RJ) & $\mathrm{R} \$$ \\
\hline Processos analisados: 2.261 & $100,0 \%$ & & \\
\hline Espaço amostral: 503 & $22,25 \%$ & & \\
\hline Informações completas: 381 & $16,85 \%$ & & \\
\hline $\begin{array}{l}\text { Expectativa de benefícios a pagar - valor presente } \\
\text { - (a) }\end{array}$ & & $71.976 .089,703405$ & 139.432.079,07 \\
\hline Valor nominal médio de um processo - (b) & & & $1.422,09$ \\
\hline $\begin{array}{l}\text { Valor médio atualizado por mês (considera como divisor } \\
\text { a média dos meses de benefícios a pagar - futuro) } \\
\text { - (c) }\end{array}$ & & $292.520,095591$ & $566.669,92$ \\
\hline $\begin{array}{l}\text { Valor médio atualizado por processo (considera como } \\
\text { divisor o } \mathrm{n}^{\circ} \text { de expedientes com informações completas) } \\
\text { de benefícios a pagar - futuro - }(\mathrm{d})\end{array}$ & & $188.913,621269$ & $365.963,46$ \\
\hline $\begin{array}{l}\text { Valor médio dos proventos de aposentadoria atualizados } \\
\text { por processo/mês }\end{array}$ & & 767,579119 & $1.486,95$ \\
\hline $\begin{array}{l}\text { Idade média de aposentadoria: } \\
\text { Homens } \\
\text { Mulheres }\end{array}$ & $\begin{array}{l}59,762 \\
56,596 \\
\end{array}$ & & \\
\hline $\begin{array}{l}\text { Média de meses a pagar }-(\mathrm{e}) \text { : } \\
\text { Homens }-10,732 \text { anos } \\
\text { Mulheres }-20,114 \text { anos }\end{array}$ & $\begin{array}{l}139,511 \\
261,484\end{array}$ & & \\
\hline
\end{tabular}

Fonte: Papéis de trabalho do técnico a partir de relatório do Scap.

Obs.: Convém complementar informações nas células do quadro no 5 , de acordo com os itens (a), (b), (c), (d) e (e):

a: Fonte: somente os processos com os dados completos.

b: Idem.

c: Idem sobre fonte. Impacto esperado nos desembolsos mensais. ativado.

$\mathrm{d}$ : Valor médio a pagar por processo para o futuro, i.e., enquanto o benefício estiver

e: Expectativa média de vida após a aposentadoria. 
Quadro 6

Análise resumida para o universo em estudo - informações relativas a maio/dez. 2009 - 3a IGP

Processos de aposentadoria analisados pela 3a IGP no período de 1으 de maio a 10 de dezembro de 2009

\begin{tabular}{|l|r|r|}
\hline \multicolumn{2}{|c|}{ ESTENDENDO AO UNIVERSO DA PESQUISA } & R\$ \\
\hline \multicolumn{1}{|c|}{ INFORMAÇÕES } & UFIR (RJ) & $827.443 .387,87$ \\
\hline $\begin{array}{l}\text { Expectativa de benefícios a valor presente a pagar no universo } \\
\text { aposentadoria - informações completas - (f) }\end{array}$ & $427.133 .697,688712$ & $3.362 .836,46$ \\
\hline $\begin{array}{l}\text { Valor médio atualizado por mês (considera como divisor a média } \\
\text { dos meses a pagar - futuro) - (g) }\end{array}$ & $1.735 .926,341553$ & $365.963,46$ \\
\hline $\begin{array}{l}\text { Valor médio atualizado por processo (considera como divisor o } \\
\text { universo em estudo - total de expedientes) de benefícios a pagar } \\
- \text { futuro - }(\mathrm{h})\end{array}$ & $188.913,621269$ \\
\hline
\end{tabular}

Fonte: Papéis de trabalho do técnico a partir de relatório do Scap.

Obs.: Convém complementar informações nas células do quadro no 6 , de acordo com os itens (f), (g) e (h):

f: Base de inferências: processos com dados completos.

g: Idem sobre dados completos. Impactos esperados nos desembolsos mensais. Estendendo para o universo de 2.261 processos.

h: Valor médio a pagar por processo para o futuro, i.e., enquanto benefício ativado. IBGE: expectativa de vida distinta — homem e mulher.

\section{Um ensaio de custos das análises dos atos de aposentadoria a cargo da $3^{\underline{a}}$ IGP}

Os custos de material de expediente levaram em consideração o material consumido no período em análise, em moeda corrente, dividido pelo total de processos que foram trabalhados (todas as naturezas) e multiplicado pelo total de processos da atividade de fiscalização dos atos de aposentadoria, o que totalizou $\mathrm{R} \$ 4.835,98$, como apresentado no quadro 7.

\section{Quadro 7}

Apropriação dos custos de material de expediente aplicados à atividade aposentadoria - maio/dez. 2009 - 3a IGP

\begin{tabular}{|l|r|}
\hline \multicolumn{1}{|c|}{ DESCRIÇÃO } & $\mathrm{R} \$$ \\
\hline Total de material enviado à 3a IGP - em R\$ & $5.446,45$ \\
\hline Estoque final em dez. 2009 & 191,25 \\
\hline Custo do material aplicado em processos & $5.255,20$ \\
\hline Custo do material aplicado na atividade aposentadoria - (R\$ / 2.457)*2.261 & $4.835,98$ \\
\hline
\end{tabular}

Fonte: Papéis de trabalho a partir de relatório de requisições de almoxarifado. 
Da pesquisa empreendida com os servidores que trabalharam os expedientes de aposentadoria no período em análise, mediante questionário de análise funcional e considerando as tabelas de cargos e salários, concluiu-se que a mão de obra direta empregada na atividade da fiscalização dos atos de aposentadoria é como se apresenta no quadro abaixo, já incluindo a provisão mensal referente ao décimo terceiro salário.

$$
\text { Quadro } 8
$$

Apropriação dos custos de mão de obra direta aplicados à atividade aposentadoria - maio/dez. 2009 - 3a IGP

\begin{tabular}{|c|c|c|c|c|c|c|c|c|}
\hline \multicolumn{9}{|c|}{ CUSTO DA MÃO DE OBRA DIRETA DA ATIVIDADE } \\
\hline MAIO & JUN. & JUL. & AGO. & SET. & OUT. & NOV. & DEZ. & SOMA \\
\hline \multicolumn{3}{|c|}{ A partir de 31/8/2009 } & 288,48 & $8.654,47$ & $9.450,29$ & $8.750,63$ & $2.096,75$ & $29.240,62$ \\
\hline \multicolumn{4}{|c|}{ A partir de 2/9/2009 } & 24.186,95 & $27.232,10$ & $26.126,54$ & $7.837,96$ & $85.383,55$ \\
\hline A partir de & $1 / 7 / 2009$ & $8.995,61$ & $17.991,22$ & $15.537,87$ & $26.744,60$ & $25.639,04$ & $8.546,35$ & $103.454,69$ \\
\hline $19.962,03$ & $19.962,03$ & $3.838,85$ & 0,00 & 0,00 & $21.748,27$ & $20.855,15$ & 838,38 & $87.204,71$ \\
\hline $9.285,40$ & $10.349,36$ & 728,31 & \multicolumn{5}{|c|}{ Vinculado à atividade até 12/7/2009 } & $20.363,07$ \\
\hline $13.255,34$ & $13.255,34$ & $13.255,34$ & $13.255,34$ & $13.255,34$ & $14.474,22$ & $12.940,46$ & $3.697,28$ & $97.388,66$ \\
\hline $9.518,54$ & $6.853,35$ & $10.280,02$ & \multicolumn{5}{|c|}{ Vinculado à atividade até 31/7/2009 } & $26.651,91$ \\
\hline $13.814,21$ & $14.374,21$ & $5.525,68$ & \multicolumn{5}{|c|}{ Vinculado à atividade até 12/7/2009 } & $33.714,10$ \\
\hline $65.835,52$ & $64.794,29$ & $42.623,81$ & $31.535,04$ & $61.634,63$ & $99.649,48$ & $94.311,82$ & $23.016,72$ & $483.401,31$ \\
\hline
\end{tabular}

Fonte: Papéis de trabalho do técnico a partir de questionários preenchidos pelos servidores e tabelas de salários TCE. Obs.: a última linha é soma ou total.

Lança-se mão dos mesmos instrumentos de pesquisa (questionário de análise funcional e tabelas de cargos e salários) para a quantificação dos gastos de mão de obra indireta, quais sejam, os salários dos inspetores gerais e protocolo da $3^{\text {a }}$ IGP, bem como dos revisores dos expedientes na SUP. Os salários indiretos da IGP foram apropriados à atividade de aposentadoria, considerando o total de processos de todas as naturezas e multiplicando-se o resultado pela quantidade de expedientes de aposentadoria, como disponibilizado no quadro 9.

Quadro 9

Apropriação dos custos de mão de obra indireta aplicados à atividade aposentadoria - maio/dez. 2009 - 3a IGP

\begin{tabular}{|c|c|c|c|c|c|c|c|c|}
\hline \multicolumn{9}{|c|}{ SUPERVISORES/PROTOCOLO/MESES } \\
\hline MAIO & JUN. & JUL. & AGO. & SET. & OUT. & NOV. & DEZ. & SOMA \\
\hline $17.375,23$ & \multicolumn{7}{|c|}{ Exerceu o cargo de Inspetor Geral até 28/6/2009 } & $17.375,23$ \\
\hline $2.261,88$ & $22.072,84$ & $23.134,15$ & $22.618,82$ & $17.736,18$ & $17.494,87$ & $30.757,77$ & $7.878,73$ & $143.955,24$ \\
\hline $8.372,96$ & $7.814,77$ & $1.674,59$ & $8.527,52$ & $8.821,58$ & $9.467,74$ & $9.144,66$ & $3.902,61$ & $57.726,43$ \\
\hline $2.961,22$ & $2.961,22$ & $2.961,22$ & $2.961,22$ & $2.961,22$ & $4.186,55$ & $3.097,37$ & $1.032,46$ & $23.122,48$ \\
\hline $2.335,63$ & $2.639,07$ & $2.618,87$ & $2.388,67$ & $2.388,67$ & $2.608,31$ & $3.267,25$ & 849,33 & $19.095,80$ \\
\hline $33.306,92$ & $35.487,90$ & $30.388,83$ & $36.496,23$ & $31.907,65$ & $33.757,47$ & $46.267,05$ & $13.663,13$ & $261.275,18$ \\
\hline
\end{tabular}

Fonte: Papéis de trabalho do técnico a partir de questionários preenchidos pelos servidores e tabelas de salários TCE. Obs.: a última linha é soma ou total. 
Considerando os gastos de mão de obra direta e indireta constantes dos quadros anteriores e, ainda, o disposto no artigo $2^{\circ}$ da Lei no 5.166, de 19 de dezembro de 2007 (tabela progressiva constante do anexo único), o valor devido ao Rioprevidência a título de patronal foi apropriado à base de 5\% (quadros 10 e 11).

Quadro 10

Apropriação dos encargos patronais Rioprevidência relativos à mão de obra direta aplicados à atividade aposentadoria - maio/dez. 2009 - 3a IGP

\begin{tabular}{|c|c|c|c|c|c|c|c|c|}
\hline \multicolumn{9}{|c|}{ CUSTO DA MÃO DE OBRA DIRETA DA ATIVIDADE - ENCARGOS } \\
\hline MAIO & JUN. & JUL. & AGO. & SET. & OUT. & NOV. & DEZ. & SOMA \\
\hline \multicolumn{3}{|c|}{ A partir de 31/8/2009 } & 14,42 & 432,72 & 472,51 & 437,53 & 104,84 & $1.462,02$ \\
\hline \multicolumn{3}{|c|}{ A partir de 2/9/2009 } & & $1.209,35$ & $1.361,61$ & $1.306,33$ & 391,90 & $4.269,19$ \\
\hline \multicolumn{2}{|c|}{ A partir de 21/7/2009 } & 449,78 & 899,56 & 776,89 & $1.337,23$ & $1.281,95$ & 427,32 & $5.172,73$ \\
\hline 998,10 & 998,10 & 191,94 & 0,00 & 0,00 & $1.087,41$ & $1.042,76$ & 41,92 & $4.360,23$ \\
\hline 464,27 & 517,47 & 36,42 & \multicolumn{5}{|c|}{ Vinculado à atividade até 12/7/2009 } & $1.018,16$ \\
\hline 662,77 & 662,77 & 662,77 & 662,77 & 662,77 & 723,71 & 647,02 & 184,86 & $4.869,44$ \\
\hline 475,93 & 342,67 & 514,00 & \multicolumn{5}{|c|}{ Vinculado à atividade até 31/7/2009 } & $1.332,60$ \\
\hline 690,71 & 718,71 & 276,28 & \multicolumn{5}{|c|}{ Vinculado à atividade até 12/7/2009 } & $1.685,70$ \\
\hline $3.291,78$ & $3.239,72$ & $2.131,19$ & $1.576,75$ & $3.081,73$ & $4.982,47$ & $4.715,59$ & $1.150,84$ & $24.170,07$ \\
\hline
\end{tabular}

Fonte: Papéis de trabalho do técnico a partir de questionários preenchidos pelos servidores e tabelas de salários TCE. Obs.: a última linha é soma ou total.

Quadro 11

Apropriação dos encargos patronais Rioprevidência relativos à mão de obra indireta aplicados à atividade aposentadoria - maio/dez. 2009 - 3르 IGP

\begin{tabular}{|rrrrrrrrr|r|}
\hline \multicolumn{7}{|c|}{ SUPERVISORES/PROTOCOLO/MESES } & ENCARGO PATRONAL \\
\hline MAIO & JUN. & \multicolumn{1}{c|}{ JUL. } & AGO. & SET. & OUT. & NOV. & DEZ. & SOMA \\
\hline 868,76 & & Exerceu O cargo de Inspetor Geral até $28 / 5 / 2009$ & & 868,76 \\
113,09 & $1.103,64$ & $1.156,71$ & $1.130,94$ & 886,81 & 874,74 & $1.537,89$ & 393,94 & $7.197,76$ \\
418,65 & 390,74 & 83,73 & 426,38 & 441,08 & 473,39 & 457,23 & 195,13 & $2.886,33$ \\
151,73 & 151,73 & 151,73 & 151,73 & 151,73 & 214,51 & 158,71 & 52,90 & $1.184,77$ \\
119,68 & 135,22 & 134,19 & 122,39 & 122,39 & 133,65 & 167,41 & 43,52 & 978,45 \\
$1.671,91$ & $1.781,33$ & $1.526,36$ & $1.831,44$ & $1.602,01$ & $1.696,29$ & $2.321,24$ & 685,49 & $13.116,07$ \\
\hline
\end{tabular}

Fonte: Papéis de trabalho do técnico a partir de questionários preenchidos pelos servidores e tabelas de salários TCE. Obs.: a última linha é soma ou total.

Os gastos indiretos aplicados aos processos, quais sejam, aqueles referentes aos custos fixos (luz, água, telefonia e serviço de limpeza), bem como os serviços prestados como apoio nas atividades de fiscalização e análise processual (segurança - bombeiros - , recep- 
ção - portaria —, informática e protocolo geral), assim considerados os valores brutos de remuneração, décimo terceiro salário provisionado mês a mês e o valor do Rioprevidência patronal, calculado como apresentado antes, foram apropriados na atividade aposentadoria como demonstrado no quadro 12, sendo a base de rateio o valor do gasto por real da folha de pagamento.

$$
\text { Quadro } 12
$$

Apropriação dos custos fixos e gastos indiretos aplicados à atividade aposentadoria - maio-dez./2009 - 3a IGP

\begin{tabular}{|c|c|c|c|c|c|c|c|c|c|}
\hline \multicolumn{10}{|c|}{ CUSTOS INDIRETOS DA ATIVIDADE - SERVIÇOS DISPONÍVEIS } \\
\hline & MAIO & JUN. & JUL. & AGO. & SET. & OUT. & NOV. & DEZ. & SOMA \\
\hline RECEPÇÃO & $1.651,67$ & $1.642,88$ & $1.221,12$ & $1.143,94$ & $1.609,44$ & $2.301,20$ & $2.373,1$ & 617,89 & $12.561,24$ \\
\hline SEGURANÇA & $1.278,21$ & $1.241,16$ & 914,54 & 853,82 & $1.197,38$ & $1.664,18$ & $1.706,57$ & 443,42 & $9.299,28$ \\
\hline CPD - INFO. & $4.362,57$ & $4.612,48$ & $3.241,45$ & $3.080,39$ & $4.212,79$ & $5.996,27$ & $6.179,28$ & $1.591,46$ & $33.276,69$ \\
\hline PROT. GERAL & $4.026,27$ & $3.945,14$ & $2.990,34$ & $2.778,50$ & $3.810,66$ & $5.311,42$ & $5.758,18$ & $1.478,22$ & $30.098,73$ \\
\hline LIMPEZA & 641,98 & 628,47 & 471,33 & 439,70 & 609,56 & 800,53 & 843,89 & 219,83 & $4.655,29$ \\
\hline LUZ & 614,01 & 587,41 & 406,67 & 395,47 & 549,19 & 684,68 & 840,20 & 182,98 & $4.260,61$ \\
\hline ÁGUA & 58,45 & 50,27 & 41,83 & 33,74 & 49,78 & 66,5 & 70,75 & 19,42 & 390,74 \\
\hline TELEFONIA & 334,23 & 340,70 & 196,41 & 223,60 & 387,58 & 410,01 & 420,21 & 121,10 & $2.433,84$ \\
\hline OUTROS & 0,00 & 0,00 & 0,00 & 0,00 & 0,00 & 0,00 & 0,00 & 0,00 & 0,00 \\
\hline SOMA & $12.967,39$ & $13.048,51$ & $9.483,69$ & $8.949,16$ & $12.426,38$ & $17.234,79$ & $18.192,18$ & $4.674,32$ & $96.976,42$ \\
\hline
\end{tabular}

Fonte: Papéis de trabalho do técnico a partir de relatórios exarados pela SGA. Obs.: a última linha é soma ou total.

Considerando toda a análise empreendida, o custo total da atividade de aposentadoria relativa à $3^{\text {a }}$ IGP totalizou $\mathrm{R} \$ 883.775,04$, como sintetizado no quadro 13 .

Quadro 13

Síntese dos custos apurados na atividade aposentadoria - maio/dez. 2009 - 3a IGP

\begin{tabular}{|c|c|c|c|c|c|c|c|}
\hline \multicolumn{8}{|c|}{ APURAÇÃO DO CUSTO POR PROCESSO - ATIV. APOSENTADORIA - 3a IGP - MAIO A DEZ. 2009} \\
\hline DESCRIÇÃO & MCD & $\mathrm{MCl}$ & $\begin{array}{c}\text { PATR } \\
- \text { MDC }\end{array}$ & $\begin{array}{l}\text { PATR } \\
-\mathrm{MCl}\end{array}$ & GIP & MAT & SOMA \\
\hline $\begin{array}{l}\text { MÃO DE OBRA DIRETA } \\
(M D)\end{array}$ & $483.401,35$ & & & & & & $483.401,35$ \\
\hline $\begin{array}{l}\text { MÃO DE OBRA INDIRETA } \\
(\mathrm{MOI})\end{array}$ & & $261.275,15$ & & & & & $261.275,15$ \\
\hline $\begin{array}{l}\text { ENCARGOS DIRETOS } \\
\text { - PATRONAL }\end{array}$ & & & $24.170,07$ & & & & $24.170,07$ \\
\hline $\begin{array}{l}\text { ENCARGOS INDIRETOS } \\
\text { - PATRONAL }\end{array}$ & & & & $13.116,07$ & & & $13.116,07$ \\
\hline
\end{tabular}




\begin{tabular}{|c|c|c|c|c|c|c|c|}
\hline \multicolumn{8}{|c|}{ APURAÇÃO DO CUSTO POR PROCESSO - ATIV. APOSENTADORIA - 3a IGP - MAIO A DEZ. 2009} \\
\hline DESCRIÇÃO & MCD & $\mathrm{MCl}$ & $\begin{array}{c}\text { PATR } \\
- \text { MDC }\end{array}$ & $\begin{array}{l}\text { PATR } \\
-\mathrm{MCl}\end{array}$ & GIP & MAT & SOMA \\
\hline $\begin{array}{l}\text { GASTOS INDIRETOS } \\
\text { - SERVIÇOS }\end{array}$ & & & & & $96.976,42$ & & $96.976,42$ \\
\hline $\begin{array}{l}\text { MATERIAL DIRETO - } \\
\text { EXPEDIENTES }\end{array}$ & & & & & & $4.835,98$ & $4.835,98$ \\
\hline SOMA & $483.401,35$ & $261.275,15$ & $24.170,07$ & $13.116,07$ & $96.976,42$ & $4.835,98$ & $883.775,04$ \\
\hline
\end{tabular}

Conclusão:

Custo por processo do universo/aposentadoria: $\mathrm{R} \$$ 390,88

Relação custo total/retorno social do universo em estudo: aposentadoria: 0,11\%

Relação retorno do universo em estudo: aposentadoria/custo total: 936,26 vezes

Custo por milhão de reais analisados: $\mathrm{R} \$ 1.068,08$

Fonte: Papéis de trabalho do técnico a partir das planilhas de custos

O quadro apresentado pode ser melhor visualizado no gráfico:

$$
\text { Gráfico }
$$

\section{Apuração de custos - atividade aposentadoria - maio/dez. 2009 - 3a IGP}

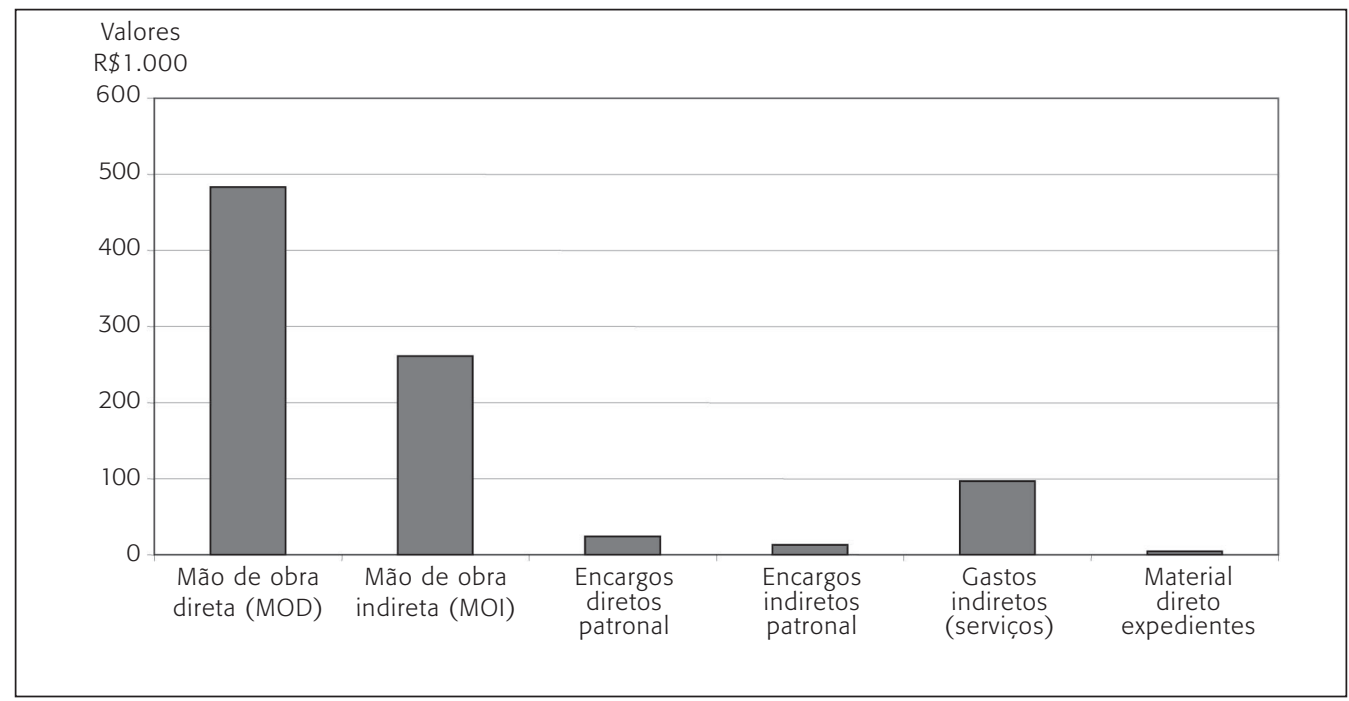

Fonte: Papéis de trabalho do técnico atuante, a partir das planilhas de custos.

É necessário destacar que a obtenção dos valores dos custos incorridos demandou tempo demasiado. Caso houvesse um sistema de folha de pagamento já visando a uma análise de custos e um sistema implantado com essa finalidade específica, minimizariam a coleta e otimizariam a análise. Destarte, além dos valores de depreciação e/ou amortização não considerados no estudo, é forçoso aceitar uma margem de erro, considerando que os valores foram obtidos mediante ques- 
tionário destinado aos servidores envolvidos direta e indiretamente na atividade e, ainda, que o percentual do patronal incidiu sobre o valor bruto da folha da remuneração, não considerando ser o servidor optante, ou não, da incidência previdenciária sobre o cargo em comissão.

\section{Quadro 14}

Planilha exame dos atos de aposentadoria: retorno socioeconômico $\times$ custo processual

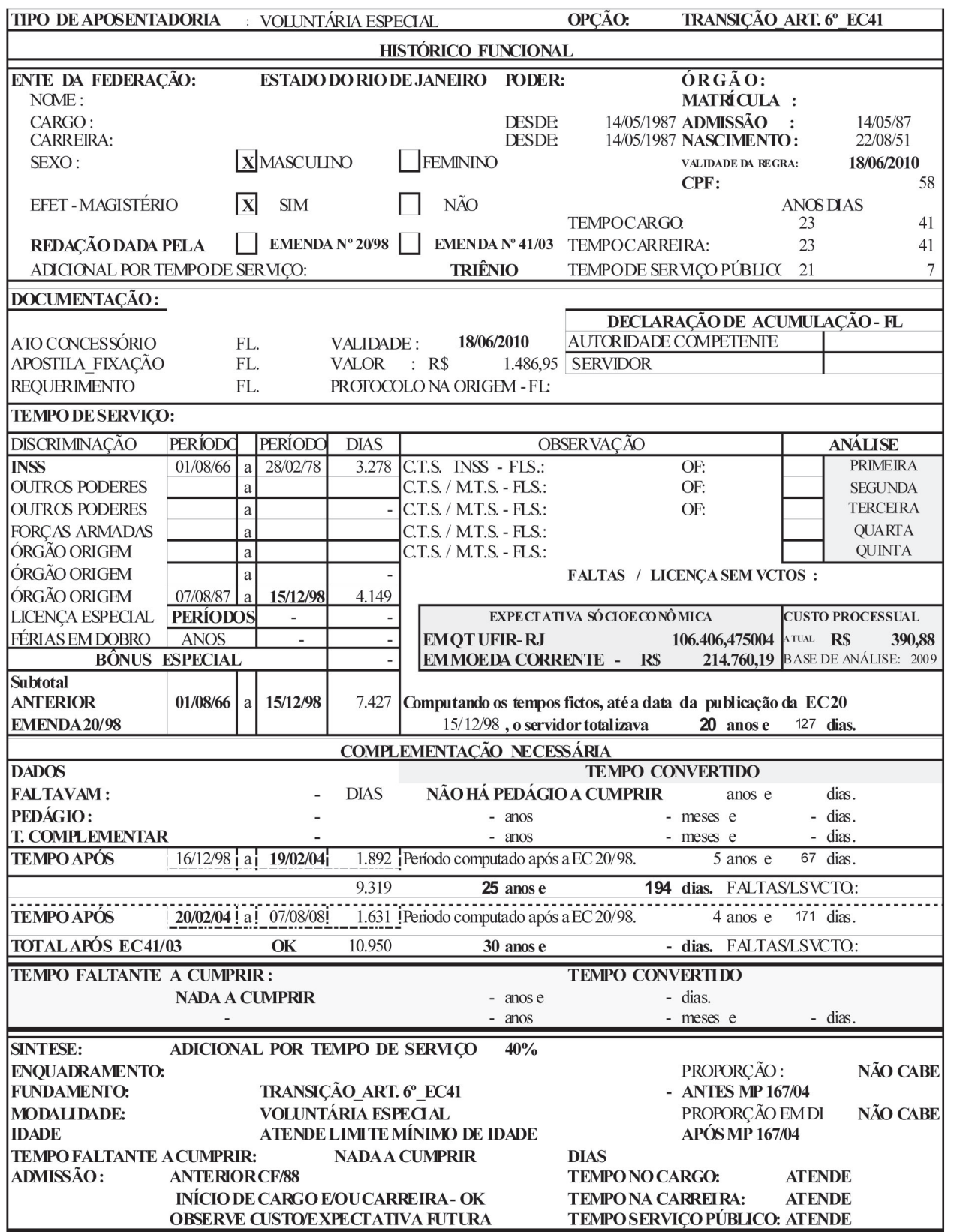

Fonte: Papéis de trabalho do técnico a partir das análises das planilhas de custos e de atos de aposentadorias no Infobase. 


\section{Em busca de possíveis conclusões}

\section{Refletindo sobre o caso}

A ação fiscalizadora do Tribunal, no tocante à área de pessoal, é propiciada pelas competências estabelecidas no art. 122 c/c o art. 123, incisos I, II, III, IV e V, ambos da Constituição Estadual, porém, se não é procedida, torna-se letra morta. Nesse caso, conforme alerta Hood (2000), a "arte de planejar e implementar" precisa ser praticada no que é propiciado, daí a justificativa deste estudo do caso, com análise da realidade concreta e sugestões práticas, porque pode se constituir em subsídios técnicos ao implemento das ações de controle da competência da Corte de Contas, enfocada na área de fiscalização de atos de pessoal.

Essa iniciativa constata a viabilidade de não limitar essa função à formalidade do registro em cumprimento ao princípio da legalidade, mas incluir a geração de informação gerencial que possa nortear decisões a serem tomadas em relação a inspeções e a definições de prioridades, como a de uma melhor alocação dos recursos disponíveis, em atendimento ao princípio da eficiência.

Nessa linha mestra, a análise dos atos da amostra estudada aponta para um inexpressivo percentual de ilegalidades que levaram à recusa de registro, o que pode sugerir uma análise que conceda maior autonomia ao inspetor nos serviços de campo, podendo apresentar no bojo do relatório de inspeção sua conclusão em relação aos atos, submetendo ao Plenário para o registro ou a promoção do processo. Além disso, é o alto índice de atos registrados, isto é, concluídos pela legalidade, que leva a apontar para a possibilidade, ou até para a necessidade/oportunidade da automação dessa atividade constitucional do TCE/RJ. O emprego de sistema informatizado - recursos da Tecnologia da Informação (TI) - otimizaria a análise em termos de eficiência, eficácia e efetividade, mediante controle mais próximo, desde o início, disponibilizando recursos humanos, financeiros e econômicos para outras atividades de fiscalização que demandem maior atuação presencial do corpo técnico, como inspetores/auditores, à medida que assegure a regularidade do sistema.

Constatou-se, pois, que a análise dos atos de aposentadoria comporta maior amplitude e profundidade do que o limite do registro, consubstanciando relatórios com enfoque gerencial de informações quantitativas e qualitativas. Tais relatórios gerenciais podem ser robustecidos com uma análise de custos.

O ensaio de custos da atividade do grupo de trabalho sobre os processos de aposentadoria na terceira 3플 IGP revela que, ainda que compreendidos os gastos indiretos, os custos são ínfimos em comparação com o benefício gerado para o futuro.

Para a implantação do esperado subsistema de custos, faz-se necessário que o sistema contábil do TCE esteja adequado às NBCASP, assim como o sistema de folha de pagamento, isto é, que estejam interligados, adotando-se uma mesma linguagem: a de custos. Note-se, porém, que se trata de centro de custos ou centros de atividades, o que difere de lotação e/ou localização. 
Nas palavras de Paulo Feijó, coordenador do Tesouro Nacional, em texto de apoio usado pelo palestrante de conteúdo especializado, veiculado em sala de aula:

é preciso considerar que a medida da eficiência não está restrita a conceitos orçamentários e financeiros. Tanto nas organizações públicas como nas privadas é preciso absorver os conceitos de custos, de restrições e de oportunidade, uma vez que não pode existir um sistema eficiente de controle interno que não seja sustentado por uma contabilidade patrimonial que atue na medição integral e real do patrimônio (STN/CFC, 2010:26): 2008).

Essa nova expectativa sobre os atos dos administradores públicos passa a avaliá-los não somente quanto à legalidade, mas pela eficiência e eficácia de suas ações, e exige dos gestores novas escolhas gerenciais sobre as Inspetorias de Controle de Pessoal, que migram de uma postura cartorial para a prática da moderna teoria da administração pública, não caricaturada pelo gerencialismo, mas no sentido do servir público, como espírito que a anime e que oriente o servidor para o pleno exercício da cidadania.

Mesmo diante do desafio da prática da gestão pública e da complexidade das questões que preocupam teóricos do porte de Friederickson e Smith, Harmon, Hood, Martins, Miller e Fox, um simples exemplo aqui ilustrado pelo ensaio de custos, sobre a atividade de aposentadoria efetuada pela 3a IGP, pôde revelar que o custo representa um instrumento em potencial de boas práticas na gestão.

Destarte, poder-se-ia adotar a análise dos atos de aposentadoria, fixação e/ou refixação de proventos, no momento de inspeção, podendo exercer seu caráter fiscalizatório com um sentido orientativo, sanando, ainda, no serviço de campo, as falhas identificadas, que reduzem os custos internos do TCE e dos jurisdicionados com relação aos serviços de expedientes e de transportes - material e humano - até que se desenvolva o sistema automatizado de exame dos atos de pessoal, inclusive aposentadoria. Essa postura, porém, não prescinde de um sistema de custos que possibilite a análise dos valores envolvidos em relação ao retorno socioeconômico dessa competência do TCE/RJ.

\section{Considerações finais}

Nesse ponto, é possível dizer que a reação de desconforto do acordar-se misturado no mundo, em relação à atmosfera ou âmbito das ideias, desvela o descolamento em que se vive como ser humano, em relação ao que lhe é próprio, concreto e sutil na expectativa de cidadania e na possibilidade do servir público.

A precariedade da autopercepção, assustada com as implicações da compreensão e insistindo no simplismo da dicotomia que fantasiosa e momentaneamente tranquiliza, pode contribuir para a criticada e praticada separação teoria e prática na administração pública e, somada ao viés da excludência teórica, vai impedindo possíveis pontes para espaços comuns entre gerenciar e administrar, em busca de relação autêntica com o mundo da vida, onde se abrigam o eu e o outro, na expectativa comum por cidadania. 
Reportando-se a Friederickson e Smith, não há que se temer a multiplicidade de conhecimentos e ações na gestão pública, porque a reflexão que este estudo possibilita leva a perceber que a interpretação de uma confusão fragilizadora é equivocada. Ao contrário, há sim a possibilidade de bases mais consistentes para leitura e análise, por exemplo, dos atos de aposentadoria.

A consciência de que a discussão não está esgotada com essa investida sugere, ainda, a realização de estudos quanto à organização de inspeções a serem efetuadas nos órgãos de pessoal, dentro da programação regular de fiscalização do Tribunal, a fim de verificar a legalidade e a regularidade dos atos de concessão de benefícios previdenciários e despesas em execução, com uma postura de relatório mais gerencial, reduzindo, sobremaneira, a carga de processos junto ao Corpo Deliberativo da Casa.

Apresentados pelo menos os primeiros resultados do caso e as primeiras reflexões sobre o que foi obtido, resta prosseguir tanto na labuta contra o vício de excludências teóricas, quanto na vigilância diante de possíveis conciliações satisfeitas com legalismos e metodologismos ou interesses desorientados do que é público, na verdade, descolados da concretude do povo.

\section{Referências}

AMAZON. Disponível em: <www.amazon.com/gp/product/0803970080/ref=pd_lpo_k2_dp_sr_ 2?pf_rd_p=1278548962\&pf_rd_s=lpo-top-stripe-1\&pf_rd_t=201\&pf_rd_i $=0673390225 \& p f \_r d$ $\mathrm{m}=$ ATVPDKIKX0DER\&pf_rd_r=1MKP85VPAWPYOPPRQ4N5\#reader_0803970080 > . Acesso em: 24 jun. 2011.

ARENDT, H. A condição humana. Tradução de Roberto Raposo. Rio de Janeiro: Forense, 2003.

BERTERO, O.C. O paradoxo da teorização e da prática administrativa. In: VASCONCELLOS, F.C.; VASCONCELLOS, I.F.G. (Org.). Paradoxos organizacionais: uma visão transformacional. São Paulo: Thomson, 2004.

BRASIL. Constituição da República Federativa do Brasil: promulgada em 5 de outubro de 1988. Obra coletiva com a colaboração de Antonio Luiz de Toledo Pinto, Márcia Cristina Vaz dos Santos Windt e Lívia Céspedes. 42. ed. Atual. e ampl. São Paulo: Saraiva, 2009. (Saraiva de Legislação).

BRASIL. Lei Complementar no 101, 4/5/00. Estabelece normas de finanças públicas voltadas para a responsabilidade na gestão fiscal e dá outras providências. Disponível em: <BRASILwww.planalto. gov.br/ccivil_03/Leis/LCP/Lcp101.htm>. Acesso em: 24 jun. 2011.

BRASIL. Manual de contabilidade aplicada ao setor público: aplicado à União, aos estados, ao Distrito Federal e aos municípios. Procedimentos contábeis orçamentários/Ministério da Fazenda, Secretaria do Tesouro Nacional. 2. ed. Brasília. Secretaria do Tesouro Nacional, Coordenação-Geral de Contabilidade, 2009. v. 1. 
BRASIL. Manual de contabilidade aplicada ao setor público: aplicado à União, aos Estados, ao Distrito Federal e aos Municípios. Procedimentos contábeis patrimoniais / Ministério da Fazenda, Secretaria do Tesouro Nacional. 2. ed. Brasília: Secretaria do Tesouro Nacional, Coordenação-Geral de Contabilidade, 2009. v. 2.

BRASIL. Manual de contabilidade aplicada ao setor público: aplicado à União, aos estados, ao Distrito Federal e aos municípios. Procedimentos contábeis específicos/Ministério da Fazenda, Secretaria do Tesouro Nacional. 2. ed. Brasília: Secretaria do Tesouro Nacional, Coordenação-Geral de Contabilidade, 2009. v. 3.

BRASIL. Manual de contabilidade aplicada ao setor público: aplicado à União, aos estados, ao Distrito Federal e aos municípios. Plano de contas aplicado ao setor público/Ministério da Fazenda, Secretaria do Tesouro Nacional. 2. ed. Brasília: Secretaria do Tesouro Nacional, Coordenação-Geral de Contabilidade, 2009. v. 4.

BRASIL. Manual de contabilidade aplicada ao setor público: aplicado à União, aos estados, ao Distrito Federal e aos municípios. Demonstrações contábeis aplicadas ao setor público/Ministério da Fazenda, Secretaria do Tesouro Nacional. 2. ed. Brasília: Secretaria do Tesouro Nacional, Coordenação-Geral de Contabilidade, 2009. v. 5.

BRESSER-PEREIRA, L.C. Gestão do setor público: estratégia e estrutura para um novo Estado. In: BRESSER-PEREIRA, L.C.; SPINK, P.K. Reforma do Estado e administração pública gerencial. 7. ed. Rio de Janeiro: Editora FGV, 2006. cap. 2, parte 4.

CAMUS, Albert. O mito de Sísifo: ensaio sobre o absurdo. Lisboa: Livros do Brasil, 2002.

CAMUS, Albert. O mito de Sísifo: ensaio sobre o absurdo. Disponível em: < http://filosofocamus. sites.uol.com.br/txtmitosisifo.htm 24-06-2011>. Acesso em: 24 jun. 2011.

CAVALCANTI, B.S. A gerência equalizadora: estratégias de gestão no setor público. In: MARTINS, P.; PIERANTI, O. Estado e gestão pública: visões do Brasil contemporâneo. 2. ed. Rio de Janeiro: Editora FGV, 2006. cap. 12.

CRUZ, F. da; NETO, O.A.P. Contabilidade de custos para entidades estatais: metodologia e casos simulados. Belo Horizonte: Fórum, 2007.

DEJOURS, C. Intelligence pratique et sagese pratique: deux dimensions meconnues du travail reel. Educacion Permanente, n. 116, 1993.

FRAGA, V.F. Gestão pela formação humana: uma abordagem fenomenológica. São Paulo: Manole, 2009.

FRIEDERICKSON, H.G.; SMITH, K.B. The public administration theory primer. Cambridge, MA.: Perseus Books Group, 2003.

GULICK, L.; URWICK, L. (Ed.). Papers on the science of administration. New York: Institute of Public Administration, 1937. 
HARMON, M. Responsibility as paradox: a critique of rational discourse on government. Thousand Oaks: Sage, 1995.

HOOD, C. The art of the State: culture, rhetoric, and public management. New York: Claredon, 2000.

JASPERS, K. Introdução ao pensamento filosófico. São Paulo: Cultrix, 1965.

KETTL, D.F. A revolução global: reforma da administração do setor público. In: BRESSER-PEREIRA, L.C.; SPINK, P.K. Reforma do Estado e administração pública gerencial. 7. ed. Rio de Janeiro: Editora FGV, 2006. cap. 4, parte 8.

MARTINS, E. Contabilidade de custos. 9. ed. São Paulo: Atlas, 2003.

MARTINS, P.E.M. et al. Estado e gestão pública: visões do Brasil contemporâneo. Rio de Janeiro: FGV, 2010.

MAUSS, C.V.; SOUZA, M.A. de. Gestão de custos aplicada ao setor público: modelo para mensuração e análise da eficiência e eficácia governamental. São Paulo: Atlas, 2008.

MILLER, H.T.; FOX, C.J. Post modern public administration. New York: ME Sharpe, 2007.

PECI, A. Além da dicotomia objetividade subjetividade. In: VIEIRA, M.M.F.; ZOUAIN, D.M. (Org.). Pesquisa qualitativa em administração: teoria e prática. Rio de Janeiro: FGV, 2004.

RIO DE JANEIRO. Constituição do Estado do Rio de Janeiro. Promulgada em 5 de outubro de 1989. Atual. Tribunal de Contas do Estado do Rio de Janeiro, 1994. (CDI).

SOUZA, S.C. de. A ética de Michel Foucault: a verdade — o sujeito — a experiência. Belém: CEJUP, 2000.

STN/CFC. Curso STN. Apostila (25-29), Brasília, FGV, out. 2010. Disponível em: <www.sigma.tce. ac.gov.br/wp-content/files/Apostila_-_Curso_de_Contabilidade_Aplicada_ao_Setor_Pblico.pdf >.

TRIBUNAL DE CONTAS DO ESTADO DO RIO DE JANEIRO. Competências dos Tribunais de Contas. Apostila atualizada em 15/8/96. (Grupo de Servidores/Professores do TCE/RJ — Coordenado pelo Professor Carlos Ramos de Barros)

TRIBUNAL DE CONTAS DO ESTADO DO RIO DE JANEIRO. Lei orgânica. Rio de Janeiro: TCE/RJ, 1991. (Lei Complementar no 63, de 1%/8/90)

TRIBUNAL DE CONTAS DO ESTADO DO RIO DE JANEIRO. Regimento interno. Rio de Janeiro: TCE/RJ, 1993. (Aprovado pela Deliberação 167, de 10/12/1992)

VASCONCELLOS, F.C.; VASCONCELOS, I.F.G. Identidade e mudança: o passado como ativo estratégico. In: VASCONCELLOS, F.C.; VASCONCELOS, I.F.G. Paradoxos organizacionais: visão transformacional. São Paulo: Thomson, 2004.

ZOUAIN, D.M.; TORRES, L. da S. O método estudo do caso: experiências práticas comprovando a influência do desenvolvimento tecnológico sobre o desenvolvimento social. In: VIEIRA, M.M.F.; 
ZOUAIN, D.M. (Org.). Pesquisa qualitativa em administração: teoria e prática. Rio de Janeiro: FGV, 2005.

WAHRLICH, B.M.S. Institucionalização da reforma administrativa: a atuação do Conselho do Serviço Público Civil e da Comissão Permanente. Revista de Administração Pública, Rio de Janeiro, v. 10, n. 4, out./dez. 1976.

WILLOUGHBY, W.F. Principes of public administration. Washington: The Brookings Institution, 1927.

WILLOUGHBY, W.F. The government of modern states. New York: D. Appleton Century, 1936.

Valderez Ferreira Fraga é professora convidada do IE-Ecex da Universidade Federal do Rio de Janeiro (UFRJ).E-mail: valorerh@centroin.com.br.

Virgílio de Oliveira Souza é docente de pós-graduação da Universidade do Grande Rio (Unigranrio). E-mail: virgils@tce.rj.gov.br. 